\title{
Grand Challenges in Translational Materials Research
}

\author{
Krisztian Kordas* \\ Microelectronics Research Unit, Faculty of Information Technology and Electrical Engineering, University of Oulu, \\ Oulu, Finland
}

Keywords: nanotechnology, energy applications of nanomaterials, microelectronics, nanoelectronics and optoelectronics devices, chemical engineering, biotechnology, environmental engineering, sustainability

\section{FROM DISCOVERIES TO COMMERCIALIZATION}

Technological progress in our modern society is driven by discovery and deployment of innovation in materials synthesis, design, and application. As such, research related to "Translational Materials," which are capable of revolutionizing the growth of our civilization play pivotal roles. A key thrust, therefore, should be geared toward the development of novel, innovative, and practical solutions that tackle challenges (Hayden, 2014). The continuous demand for having smaller, better, stronger, lighter, more durable, and efficient tools and devices often with complex functionalities requires a novel approach to advanced materials and design. While materials research is a rather broad field of science and technology, encompassing various disciplines ranging from biotechnology to electronics, and information technology, what makes translational materials research particularly important is the way of thinking and answering a question: How can we translate advances and move ahead toward commercialization? Obviously, it is not the first question what a scientist considers when working on a new topic. Maybe at the time of discovery, there is no technology yet to implement the

OPEN ACCESS

Edited by:

Jon Ajuria,

Ikerlan, Spain

Reviewed by:

Josep Albero,

Institut of Chemical Technology

(CSIC-UPV), Spain

*Correspondence:

Krisztian Kordas

krisztian.kordas@oulu.fi

Specialty section:

This article was submitted to

Translational Materials Science, a section of the journal

Frontiers in Materials

Received: 01 September 2017

Accepted: 31 October 2017

Published: 21 November 2017

Citation:

Kordas K (2017) Grand Challenges in Translational Materials Research.

Front. Mater. 4:38.

doi: 10.3389/fmats.2017.00038 theory in practice or to scale up a laboratory experiment to a pilot or industrial production. However, great inventions and discoveries shall and will find the way and this is what we ought to contribute to in our Translational Materials Science section of Frontiers in Materials.

Historically, the most important man-made materials were those used in construction, transportation, weapons and clothing, etc., putting much weight on the manufacturing of materials such as glasses, ceramics and their composites, metal alloys, and fibrous materials of natural origin. Later, in the twentieth century, the revolutionary results in physics, chemistry, and biology led to the birth of modern materials science, and let us build industries without which we cannot imagine our life as we know it today. Such development has played a key role by providing right impetus to food and pharmaceutical industries, as well as to electronics and information technology. The extremely rapid development of these latter two is unprecedented considering that the first transistor was made in 1947, and the semiconductor industry today has total annual revenue of more than 300 billion USD ${ }^{1}$ supplying components and parts for all kinds of electrical appliances.

\section{A CONTEMPORARY EXAMPLE OF A TRUE TRANSLATIONAL MATERIAL: CARBON-BASED NANOMATERIALS}

Because of the broad spectrum of materials in science and technology, the number of potentially viable new materials and associated technologies is enormous, making it impossible to provide a complete review within a single article. Here, we give only a few examples to demonstrate how new nanomaterials based on carbon nanostructures could revolutionize some selected fields in electronics, energy, chemical, and environmental applications. Since the discovery of fullerenes (1985), carbonaceous

${ }^{1}$ www.statista.com; www.statista.com/statistics/270590/global-revenue-generated-by-semiconductor-vendors-since-2009. 
materials have their renaissance, which was boosted even further after finding carbon nanotubes (1991) and later graphene (2004) and their derivatives making up a business of approximately one billion USD in 2016 only of carbon nanotubes ${ }^{2}$ used in sporting goods, battery/capacitor electrodes, in different parts of vehicles but also in electrical displays among others.

Carbon nanostructures may be synthesized by a number of different methods that are easy to scale up to produce massive amounts of materials at reasonable cost (Ajayan, 1999). Although hydrocarbons are applied as typical precursors to grow carbon nanotubes (Colomer et al., 2000), nanofibers (Huang et al., 2002), and graphene (Chae et al., 2009) on catalytic surfaces using chemical vapor deposition, one may also apply renewable raw materials such as alcohols or any other naturally occurring organics (hydrocarbons, aldehydes, or carboxylic acids, e.g., from distillation fractions of plants) (Maruyama et al., 2002; Kumar and Ando, 2005; Ghosh et al., 2009; Seo et al., 2017). Carbon nanostructures are interesting for many reasons. Made of carbon, in which the atoms are held together with strong covalent bonds, these nanostructures are of light weight and mechanically strong. While structures with large $\mathrm{sp}^{3}$ hybridized carbon fraction such as in diamond-like carbons display extreme hardness, poor electrical but excellent thermal transport; $\mathrm{sp}^{2}$-hybridized structures (e.g., carbon nanotubes and graphene) are typically flexible and show structure (and chirality)-dependent electrical behavior taking metallic, semi-metallic, or semi-conducting forms (Loiseau et al., 2006).

Owing to the colorful surface chemistry of nanostructured carbons, practically any functional group can be introduced and thus these materials may be grafted in all kinds of polymers allowing for light-weight structural, thermal, and electrical composites with enhanced features (Spitalsky et al., 2010). Dispersions of functionalized nanotubes and graphene in various solvents (Kordas et al., 2013) used as conductive inks are suitable for printing (Kordás et al., 2006) and spray coating applications (Kaempgen et al., 2005) to replace costly silver based inks and indium tin oxide coatings. This latter application is particularly important since our indium resources are becoming rapidly depleted due to the excessive use in transparent conductive touch screen panels and photovoltaic device electrodes (and improper recycling of related e-waste) making any alternative materials and technologies industrially indeed very relevant (Mohl et al., 2015; Werner et al., 2015).

When spun in microscopic fibers similar to the yarns in the textile industry, one obtains mechanically robust carbon nanotube microfiber cables with practically any length (Dalton et al., 2003) and may be, some day, even realize the vision of Richard Smalley about "space elevators." While the electrical conductivity of such nanotube fibers is not sufficient to directly replace ordinary metals ( $\mathrm{Al}$ and $\mathrm{Cu}$ ) in power electronics, however, after doping them with alkali metals or halogens, the mass normalized electrical conductivity has been shown to become comparable to those of good conductors (Salvato et al., 2001; Zhao et al., 2011). Having that accomplished, such doped macroscopic nanotube

${ }^{2}$ www.nanowerk.com; www.nanowerk.com/spotlight/spotid=23118.php. fibers suggest new perspectives for electrical cable manufacturers in the future. Another related interesting application is in traditional incandescent bulbs to replace tungsten, taking a few steps back to the roots, and reinvent carbon based filaments again (Wei et al., 2004).

Robust macroscopic carbon nanostructures and their hierarchical composites that combine various forms of carbon foams, nanotubes, and graphene offer ideal multipurpose monolith-type materials for diverse applications. These large specific surface area materials with light-weight and porous structures (even with multimodal porosity) are excellent absorbers of fluids finding use in chemical separation and environmental engineering (Pham et al., 2014). When decorating the surface of carbon with metal, metal oxide/sulfide nanoparticles, the structure becomes catalytically active resulting in new types of catalyst beds suitable for all kinds of chemical reactors (Serp et al., 2003; Halonen et al., 2010). By exploiting the electrical conductivity, in conjunction with the already mentioned advantageous properties, we end up in electrodes for electrochemical sensing (Sainio et al., 2015), energy conversion (Pham et al., 2017), storage (Talapatra et al., 2006; Pushparaj et al., 2007), and harvesting (Aitola et al., 2011).

A number of further applications have been demonstrated, and some of them are still in the pipeline waiting for exploitation and commercialization such as CMOS compatible field-emitters with high current density and low turn-on field (Sridhar et al., 2014), gas detectors (Modi et al., 2003), vertical and horizontal interconnects in integrated circuits (Li et al., 2003; Wei et al., 2004; Wang et al., 2011; Kordás et al., 2006), soft electrodes (Toth et al., 2009), heat conduction and dissipation elements in electronics packaging (Kordás et al., 2007; Liu et al., 2009), and so forth.

\section{THE GRAND CHALLENGES IN DISCOVERY AND DEVELOPMENT OF TRANSLATIONAL MATERIALS}

The list of applications with high potential and commercial relevance may be continued, and this is just an example of nanostructured carbons. Emerging classes of fascinating materials including new multifunctional electroceramics and glasses (Setter and Waser, 2000; Bai et al., 2017), synthetic (Ikkala and ten Brinke, 2002; Noriega et al., 2013), and biopolymers (Van de Velde and Kiekens, 2002; Petersson and Oksman, 2006), layered materials (Mas-Balleste et al., 2011; Muchharla et al., 2013), metamaterials (Zhang and Liu, 2008; Yu and Capasso, 2014) among many others expand the list of applications.

However, the key to the long-term success of development and deployment of Translational Materials is complex. First, one of the major bottlenecks is the lack of strategic collaboration and information exchange between academia and industry. These key players need to make sure that there is a common understanding on what academic scientists can offer and how industry research and development can propel it further to achieve competitive products. Second, funding agencies shall understand that ground breaking "applied" science is often the result of a thorough "fundamental" scientific investigation, where sometimes incremental research results can point in to the right direction. Such 
sentiments can bridge the gap between innovations and practical applications and make the road toward success a little less bumpy. There can be excellent discoveries, without sufficient funding, the promising results of basic research often will not be able to grow further to bring the fruits. Third, and very importantly, any development shall be made through considering sustainability with all its ingredients including energy efficiency as well as smart usage of abundant and renewable materials to preserve our nature and environment (Anonymous, 2017). While recycling and the overall idea of circular economy offer a momentary solution to extend the period of availability of even scarce elements, the efficiency of return is never $100 \%$, which inherently results in loosing valuable raw materials and gradual depletion of our globe's resources.

Accordingly, new technologies and materials are in constant need to complement or preferably replace old ones while maintaining or even improving the particular functionality, yet offering environmentally friendly alternatives to conventional materials

\section{REFERENCES}

Aitola, K., Halme, J., Halonen, N., Kaskela, A., Toivola, M., Nasibulin, A. G., et al. (2011). Comparison of dye solar cell counter electrodes based on different carbon nanostructures. Thin Solid Films 519, 8125-8134. doi:10.1016/j. tsf.2011.05.078

Ajayan, P. M. (1999). Nanotubes from carbon. Chem. Rev. 99, 1787-1799. doi:10.1021/cr970102g

Anonymous. (2017). A sustainable material world. Nat. Mater. 16, 691. doi:10.1038/ nmat4932

Bai, Y., Tofel, P., Palosaari, J., Jantunen, H., and Juuti, J. (2017). A game changer: a multifunctional perovskite exhibiting giant ferroelectricity and narrow bandgap with potential application in a truly monolithic multienergy harvester or sensor. Adv. Mater. 29, 1700767. doi:10.1002/adma.201700767

Chae, S. J., Gunes, F., Kim, K. K., Kim, E. S., Han, G. H., Kim, S. M., et al. (2009). Synthesis of large-area graphene layers on poly-nickel substrate by chemical vapor deposition: wrinkle formation. Adv. Mater. 21, 2328. doi:10.1002/ adma. 200803016

Colomer, J. F., Stephan, C., Lefrant, S., Van Tendeloo, G., Willems, I., Konya, Z., et al. (2000). Large-scale synthesis of single-wall carbon nanotubes by catalytic chemical vapor deposition (CCVD) method. Chem. Phys. Lett. 317, 83-89. doi:10.1016/S0009-2614(99)01338-X

Dalton, A. B., Collins, S., Munoz, E., Razal, J. M., Ebron, V. H., Ferraris, J. P., et al. (2003). Super-tough carbon-nanotube fibres - these extraordinary composite fibres can be woven into electronic textiles. Nature 423, 703. doi:10.1038/ 423703a

Ghosh, P., Soga, T., Tanemura, M., Zamri, M., Jimbo, T., Katoh, R., et al. (2009). Vertically aligned carbon nanotubes from natural precursors by spray pyrolysis method and their field electron emission properties. Appl. Phys. A 94, 51-56. doi:10.1007/s00339-008-4856-9

Halonen, N., Rautio, A., Leino, A.-R., Kyllönen, T., Tóth, G., Lappalainen, J., et al. (2010). Three dimensional carbon nanotube scaffolds as filters or catalyst support membranes. ACS Nano 4, 2003-2008. doi:10.1021/nn100150x

Hayden, O. (2014). Grand challenges for translational materials science. Front. Mater. 1:1-2. doi:10.3389/fmats.2014.00005

Huang, S. M., Dai, L. M., and Mau, A. W. H. (2002). Controlled fabrication of largescale aligned carbon nanofiber/nanotube patterns by photolithography. Adv. Mater. 14, 1140-1143. doi:10.1002/1521-4095(20020816)14:16<1140:AIDADMA1140>3.0.CO;2-5

Ikkala, O., and ten Brinke, G. (2002). Functional materials based on self-assembly of polymeric supramolecules. Science 295, 2407-2409. doi:10.1126/science. 1067794

Kaempgen, M., Duesberg, G. S., and Roth, S. (2005). Transparent carbon nanotube coatings. Appl. Surf. Sci. 252, 425-429. doi:10.1016/j.apsusc.2005.01.020 keeping both academia and industry busy for the upcoming years to work on translational research.

\section{AUTHOR CONTRIBUTIONS}

KK compiled and written the manuscript.

\section{ACKNOWLEDGMENTS}

The author thanks Professor Saikat Talapatra (Southern Illinois University, Carbondale) and Professor Robert Vajtai (Rice University, Houston) for fruitful discussion and suggestions on the manuscript.

\section{FUNDING}

Funding received from the Academy of Finland (Suplacat) and University of Oulu (MtM RC) are acknowledged.

Kordas, K., Kukkola, J., Toth, G., Jantunen, H., Szabó, M., Sápi, A., et al. (2013) "Nanoparticle dispersions," in Springer Handbook of Nanomaterials, ed. R. Vajtai (Heidelberg: Springer Verlag) 729-775.

Kordás, K., Mustonen, T., Tóth, G., Jantunen, H., Lajunen, M., Soldano, C., et al. (2006). Ink-jet printing of electrically conductive patterns of carbon nanotubes. Small 2, 1021-1025. doi:10.1002/smll.200600061

Kordás, K., Tóth, G., Moilanen, P., Kumpumäki, M., Vähäkangas, J., Uusimäki, A., et al. (2007). Chip cooling with integrated carbon nanotube microfin architectures. App. Phys. Lett. 90, 123105. doi:10.1063/1.2714281

Kumar, M., and Ando, Y. (2005). Controlling the diameter distribution of carbon nanotubes grown from camphor on a zeolite support. Carbon N. Y. 43, 533-540. doi:10.1016/j.carbon.2004.10.014

Li, J., Ye, Q., Cassell, A., Ng, H. T., Stevens, R., Han, J., et al. (2003). Bottom-up approach for carbon nanotube interconnects. Appl. Phys. Lett. 82, 2491-2493. doi:10.1063/1.1566791

Liu, J., Fu, Y., and Wang, T. (2009). "Recent progress of carbon nanotubes as cooling fins in electronic packaging," in 2008 International Conference on Electronic Packaging Technology \& High Density Packaging, Shanghai.

Loiseau, A., Launois, P., Petit, P., Roche, S., and Salvetat, J.-P. (eds) (2006). "Understanding carbon nanotubes," in Lect. Notes Phys (Berlin Heidelberg: Springer), 677.

Maruyama, S., Kojima, R., Miyauchi, Y., Chiashi, S., and Kohno, M. (2002). Lowtemperature synthesis of high-purity single-walled carbon nanotubes from alcohol. Chem. Phys. Lett. 360, 229-234. doi:10.1016/S0009-2614(02)00838-2

Mas-Balleste, R., Gomez-Navarro, C., Gomez-Herrero, J., and Zamora, F. (2011). 2D materials: to graphene and beyond. Nanoscale 3, 20-30. doi:10.1039/ c0nr00323a

Modi, A., Koratkar, N., Lass, E., Wei, B. Q., and Ajayan, P. M. (2003). Miniaturized gas ionization sensors using carbon nanotubes. Nature 424, 171-174. doi:10.1038/nature01777

Mohl, M., Dombovari, A., Vajtai, R., Ajayan, P. M., and Kordas, K. (2015). Selfassembled large scale metal alloy grid patterns as flexible transparent conductive layers. Sci. Rep. 5, 13710. doi:10.1038/srep13710

Muchharla, B., Pathak, A., Liu, Z., Song, L., Jayasekera, T., Kar, S., et al. (2013). Tunable electronics in large-area atomic layers of boron-nitrogen-carbon. Nano Lett. 13, 3476-3481. doi:10.1021/nl400721y

Noriega, R., Rivnay, J., Vandewal, K., Koch, F. P. V., Stingelin, N., Smith, P., et al. (2013). A general relationship between disorder, aggregation and charge transport in conjugated polymers. Nature Mater. 12, 1038-1044. doi:10.1038/nmat3722

Petersson, L., and Oksman, K. (2006). Biopolymer based nanocomposites: comparing layered silicates and microcrystalline cellulose as nanoreinforcement. Composite Sci. Technol. 66, 2187-2196. doi:10.1016/j.compscitech.2005.12.010

Pham, T. N., Samikannu, A., Kukkola, J., Rautio, A. R., Pitkanen, O., Dombovari, A., et al. (2014). Industrially benign super-compressible piezoresistive carbon 
foams with predefined wetting properties: from environmental to electrical applications. Sci. Rep. 4, 6933. doi:10.1038/srep06933

Pham, T. N., Sharifi, T., Sandström, R., Siljebo, W., Shchukarev, A., Kordas, K., et al. (2017). Robust hierarchical 3D carbon foam electrode for efficient water electrolysis. Sci. Rep. 7, 6112. doi:10.1038/s41598-017-05215-1

Pushparaj, V. L., Shaijumon, M. M., Kumar, A., Murugesan, S., Ci, L., Vajtai, R., et al. (2007). Flexible energy storage devices based on nanocomposite paper. Proc. Nat. Acad. Sci. U.S.A. 104, 13574-13577. doi:10.1073/pnas. 0706508104

Sainio, S., Palomaki, T., Tujunen, N., Protopopova, V., Koehne, J., Kordas, K., et al. (2015). Integrated carbon nanostructures for detection of neurotransmitters. Mol. Neurobiol. 52, 859-866. doi:10.1007/s12035-015-9233-Z

Salvato, M., Lucci, M., Ottaviani, I., Cirillo, M., Tamburri, E., Cianchetta, I., et al. (2001). Effect of potassium doping on electrical properties of carbon nanotube fibers. Phys. Rev. B 84, 233406. doi:10.1103/PhysRevB.84.233406

Seo, D. H., Pineda, S., Fang, J., Gozukara, Y., Yick, S., Bendavid, A., et al. (2017). Single-step ambient-air synthesis of graphene from renewable precursors as electrochemical genosensor. Nat. Commun. 8, 14217. doi:10.1038/ ncomms 14217

Serp, P., Corrias, M., and Kalck, P. (2003). Carbon nanotubes and nanofibers in catalysis. Appl. Catal. A 253, 337-358. doi:10.1016/S0926-860X(03)00549-0

Setter, N., and Waser, R. (2000). Electroceramic materials. Acta Mater. 48, 151-178. doi:10.1016/S1359-6454(99)00293-1

Spitalsky, Z., Tasis, D., Papgelis, K., and Galiotis, C. (2010). Carbon nanotubepolymer composites: chemistry, processing, mechanical and electrical properties. Prog. Polym. Sci. 35, 357-401. doi:10.1016/j.progpolymsci.2009.09.003

Sridhar, S., Tiwary, C., Vinod, S., Taha-Tijerina, J. J., Sridhar, S., Kalaga, K., et al. (2014). Field emission with ultralow turn on voltage from metal decorated carbon nanotubes. ACS Nano 8, 7763-7770. doi:10.1021/nn500921s

Talapatra, S., Kar, S., Pal, S. K., Vajtai, R., Ci, L., Victor, P., et al. (2006). Direct growth of aligned carbon nanotubes on bulk metals. Nature Nanotech. 1, 112-116. doi:10.1038/nnano.2006.56
Toth, G., Mäklin, J., Halonen, N., Palosaari, J., Juuti, J., Jantunen, H., et al. (2009) Carbon nanotube based electrical brush contacts. Adv. Mater. 21, 2054-2058. doi:10.1002/adma.200802200

Van de Velde, K., and Kiekens, P. (2002). Biopolymers: overview of several properties and consequences on their applications. Polymer Test. 21, 433-442. doi:10.1016/S0142-9418(01)00107-6

Wang, T., Jeppson, K., Ye, L., and Liu, J. (2011). Carbon-nanotube through-silicon via interconnects for three-dimensional integration. Small 7, 2313-2317. doi:10.1002/smll.201100615

Wei, J. Q., Zhu, H. W., Wu, D. H., and Wei, B. Q. (2004). Carbon nanotube filaments in household light bulbs. Appl. Phys. Lett. 84, 4869-4871. doi:10.1063/1.1762697

Werner, T. T., Mudd, G. M., and Jowitt, S. M. (2015). Indium: key issues in assessing mineral resources and long-term supply from recycling. Appl. Earth Sci. 124, 213-226. doi:10.1179/1743275815Y.0000000007

Yu, N. F., and Capasso, F. (2014). Flat optics with designer metasurfaces. Nature Mater. 13, 139-150. doi:10.1038/nmat3839

Zhang, X., and Liu, Z. W. (2008). Superlenses to overcome the diffraction limit. Nat. Mater. 7, 435-441. doi:10.1038/nmat2141

Zhao, Y., Wei, J. Q., Vajtai, R., Ajayan, P. M., and Barrera, E. V. (2011). Iodine doped carbon nanotube cables exceeding specific electrical conductivity of metals. Sci. Rep. 1, 83. doi:10.1038/srep00083

Conflict of Interest Statement: The author declares that the research was conducted in the absence of any commercial or financial relationships that could be construed as a potential conflict of interest.

Copyright $\odot 2017$ Kordas. This is an open-access article distributed under the terms of the Creative Commons Attribution License (CC BY). The use, distribution or reproduction in other forums is permitted, provided the original author (s) or licensor are credited and that the original publication in this journal is cited, in accordance with accepted academic practice. No use, distribution or reproduction is permitted which does not comply with these terms. 